\title{
Development and validation of a rapid reversed-phase HPLC method for the determination of insulin from nanoparticulate systems
}

\author{
Bruno Sarmento, ${ }^{1 *}$ António Ribeiro, ${ }^{2}$ Francisco Veiga ${ }^{3}$ and Domingos Ferreira ${ }^{1}$ \\ ${ }^{1}$ Department of Pharmaceutical Technology, Faculty of Pharmacy, University of Porto, Porto, Portugal \\ ${ }^{2}$ Department of Pharmaceutical Technology, Instituto Superior de Ciências da Saúde-Norte, Gandra, Portugal \\ ${ }^{3}$ Department of Pharmaceutical Technology, Faculty of Pharmacy, University of Coimbra, Coimbra, Portugal
}

Received 9 August 2005; revised 31 October 2005; accepted 1 November 2005

\begin{abstract}
A reversed-phase high-performance liquid chromatographic (HPLC) method has been developed and validated for the determination of insulin in nanoparticulate dosage forms. Its application for the development and characterization of insulinloaded nanoparticulates composed of polyelectrolytes has also been carried out. A reversed-phase (RP) $\mathrm{C}_{18}$ column and gradient elution with a mobile phase composed of acetonitrile $(\mathrm{ACN})$ and $0.1 \%$ aqueous trifluoroacetic acid (TFA) solution at a flow rate of $1 \mathrm{~mL} / \mathrm{min}$ was used. Protein identification was made by UV detection at $214 \mathrm{~nm}$. The gradient changed from 30:70 (ACN:TFA, $\mathrm{v} / \mathrm{v})$ to $40: 60(\mathrm{v} / \mathrm{v})$ in $5 \mathrm{~min}$ followed by isocratic elution at 40:60 (v/v) for a further five minutes. The method was linear in the range of $1-100 \mu \mathrm{g} / \mathrm{mL}\left(R^{2}=0.9996\right)$, specific with a good inter-day and intra-day precision based on relative standard deviation values (less than $3.80 \%$ ). The recovery was between 98.86 and $100.88 \%$ and the detection and quantitation limits were 0.24 and $0.72 \mu \mathrm{g} / \mathrm{mL}$, respectively. The method was further tested for the determination of the association efficiency of insulin to nanoparticulate carriers composed of alginate and chitosan, as well as its loading capacity for this protein. Encapsulant release under simulated gastrointestinal fluids was evaluated. The method can be used for development and characterization of insulinloaded nanoparticles made from cross-linked chitosan-alginate. Copyright @ 2006 John Wiley \& Sons, Ltd.
\end{abstract}

KEYWORDS: alginate; chitosan; insulin; method validation; nanoparticles; RP-HPLC

\section{INTRODUCTION}

Reversed-phase HPLC, a technique used to separate proteins based on hydrophobicity, is probably the most used analytical method for separation and determination of peptides and proteins in an extensive range of applications (Aguilar, 2004). The method is powerful and sensitive, being an accurate way to measure insulin in both artificial and biological environments (Khaksa et al., 1998; Moslemi et al., 2003; Oliva et al., 2000). Also, official monographs, namely the US and European Pharmacopoeia, present HPLC methods for insulin determination. However, these methods usually require long run times and use buffers as mobile phases that are often responsible for contamination of HPLC systems due to salt precipitations.

Insulin is a protein administered subcutaneously to humans for the treatment of type I diabetes mellitus to control glucose homeostasis when pancreatic $\beta$-cells

*Correspondence to: B. Sarmento, Department of Pharmaceutical Technology, Faculty of Pharmacy, University of Porto, Porto, Portugal.

E-mail: bruno.sarmento@ff.up.pt

Abbreviations used: ACN, acetonitrile; AE, association efficiency; LC, loading capacity; TFA, trifluoroacetic acid.

Contract/grant sponsor: Fundação para a Ciência e Tecnologia. production is not enough to ensure daily needs of this hormone. It is a well characterized protein with a molecular weight of $5.8 \mathrm{kDa}$ and composed of two peptide chains, referred to as the A-chain of 21 amino acid residues and the B-chain of 30 amino acid residues. Two disulfide bridges link these chains together and another intrapeptide disulfide bond exists in the A-chain (Brange et al., 1997).

The desire of a more convenient and socially compatible route of insulin administration other than subcutaneous injection has originated several approaches to attempt its oral delivery. The association of insulin with colloidal drug carriers which might be able to protect proteins inside the intestinal tract and facilitate its transport from the gut lumen to the blood compartment has been suggested (Aboubakar et al., 2000; Michel et al., 1991). Several pre-formulation studies and in vitro and in vivo assays have been performed towards the optimization of insulin oral delivery systems (Hari et al., 1996; Marschutz and Bernkop-Schnurch, 2000; Onal and Zihnioglu, 2002; Takenaga et al., 2002), requiring appropriated and validated methods to assess truthful profiles of insulin release from delivery systems as well as its pharmacokinetic behaviour. However, it has been reported that not only analytical techniques used for the development of pharmaceuticals must be 
validated but also techniques for determination of their quality characteristics (Épshtein, 2004).

In this paper, a new rapid reversed-phase HPLC method for the determination of insulin from nanoparticulate carriers made from alginate and chitosan is described and validated. Furthermore, its application to characterization of an insulin-loaded alginate/chitosan nanoparticulate system was also evaluated. The specific application to insulin nanoparticulate dosage forms would provide a suitable way to characterize both system carrier and insulin stability after entrapment.

\section{EXPERIMENTAL}

Materials. The human insulin reference standard (lot RS0325, $7.0 \mathrm{mg}$ lyophilized human biosynthetic insulin per vial) and commercial Humulin Regular ${ }^{\circledR}(3.5 \mathrm{mg} / \mathrm{mL}$ human insulin) were kindly supplied by Lilly Farma, Portugal. Acetonitrile (LiChrosolv HPLC grade) and trifluoroacetic acid (TFA) were obtained from Merck $^{\circledR}$ (Darmstadt, Germany). Prior to use, acetonitrile and $0.1 \%$ TFA aqueous solution prepared with deionized water (Milli- $\mathrm{Q}^{\circledR}$, Moslheim, France) were filtered with a $0.45 \mu \mathrm{m}$ filter and degassed for $15 \mathrm{~min}$.

Low G-content sodium alginate $\left(F_{\mathrm{G}}=0.39\right)$ and low molecular weight chitosan $(\sim 50 \mathrm{kDa})$ were purchased from Aldrich (Oakville, Canada). Calcium chloride was obtained from Aldrich (Milwaukee, USA).

Equipment. A Varian 9012 Gradient Solvent Delivery System Varian 9012 and a Varian 9050 Variable Wavelength UV-VIS Detector (Varian ${ }^{\circledR}$, USA) were used to perform all chromatographic runs. The HPLC system was equipped with an XTerra $\mathrm{RP}_{18}$ column, $5 \mu \mathrm{m}$ particle size, $4.6 \mathrm{~mm}$ internal diameter $\times 250 \mathrm{~mm}$ length (Waters ${ }^{\circledR}$, USA) and a LiChrospher ${ }^{\circledR} 100 \mathrm{RP}_{18}, 5 \mu \mathrm{m}$ particle size guard column (Merck, Germany). Equipment control, data acquisition and integration were executed with the Star Chromatography Workstation (Varian ${ }^{\circledR}$, USA).

Chromatographic conditions. The mobile phase consisted of acetonitrile and $0.1 \%$ TFA aqueous solution initially set in the ratio $30: 70(\mathrm{v} / \mathrm{v})$, which was linearly changed to 40:60 (v/v) over $5 \mathrm{~min}$. From 5 to $10 \mathrm{~min}$ the ratio 40:60 (v/v) was kept constant. Eluent was pumped at a flow rate of $1 \mathrm{~mL} / \mathrm{min}$, the injection volume was $20 \mu \mathrm{L}$ and detection wavelength was $214 \mathrm{~nm}$. All experiments occurred at room temperature and the total area of peak was used to quantify the insulin.

These conditions were investigated to provide a simple procedure with the best peak resolution regarding symmetry and tailing, reduce run time lower the cost of analysis.

Preparation of standard solutions. Calibration curves for seven human insulin standard solutions were prepared at concentrations of $1,3,6,12.5,25,50$ and $100 \mu \mathrm{g} / \mathrm{mL}$ in USP XXVI acetate buffer $\mathrm{pH}$ 4.7. This $\mathrm{pH}$ was chosen due to the $\mathrm{pH}$ environments in which the nanoparticulate carriers were produced and in which the supernatants obtained after centrifugation were analyzed. A primary stock solution of $700 \mu \mathrm{g} / \mathrm{mL}$ was accurately prepared following by rigorous dilution with the same buffer solution to give secondary standard solutions. Humulin Regular $^{\circledR}$ was appropriately diluted to a final concentration of $35 \mu \mathrm{g} / \mathrm{mL}$. Freshly prepared stock solutions were used for all determinations and were kept at $4^{\circ} \mathrm{C}$ between each injection.

Validation of the method. The method was validated in agreement with International Conference on Harmonization guidelines (ICH, 1996), using the following analytical parameters: linearity, precision, accuracy, specificity, detection and quantitation limits and robustness. Linearity was evaluated by calculation of a regression line using least squares method. Calibration curves were obtained from seven different concentrations analyzed three times. Precision was assessed by testing the repeatability of three different standard solutions 10 times in the same day (intra-day) and by intermediate precision analyzing the same three standard solutions three times on different days (inter-day). Accuracy was tested by percentage recoveries of mean of three determinations of insulin at three different concentrations precisely prepared and by determination of the relative standard deviation (RSD). Specificity was determined by comparing nanoparticulate carrier samples with and without insulin, the latter being referred to as empty systems. Detection limit (DL) and quantitation limit (QL) were determined based on the standard deviation of the response and on the slope of the calibration curve, using the following expressions:

$$
\begin{aligned}
& \mathrm{DL}=\frac{3.3 \sigma}{S} \\
& \mathrm{QL}=\frac{10 \sigma}{S}
\end{aligned}
$$

where $\sigma$ is the standard deviation of the response and $S$ is the slope of the calibration curve. Robustness was evaluated according to the application of the method and based on the variation of the $\mathrm{pH}$ of insulin standard solutions.

Application of the method. Nanoparticulate carriers based on alginate ionotropic pre-gelation with calcium ions followed by chitosan polycationic complexation were prepared (Sarmento et al., 2004). For the preparation of insulin-loaded carriers the protein was mixed with alginate solution prior to pre-gelation step with calcium ions. Nanoparticles were isolated by centrifugation $(20,000 \times \mathrm{g} / 45 \mathrm{~min})$. Association efficiency (AE) and loading capacity (LC) of insulin to nanoparticulate carriers were obtained according to the following equations:

$$
\begin{aligned}
& \text { Total amount of insulin - } \\
& \mathrm{AE}=\frac{\text { Free insulin in supernatant }}{\text { Total amount of insulin }} \times 100 \\
& \text { Total amount of insulin - } \\
& \mathrm{LC}=\frac{\text { Free insulin in supernatant }}{\text { Total weight of nanoparticles }} \times 100
\end{aligned}
$$

These parameters were analyzed in both fresh nanoparticulate carriers and after one month of shelf life. All insulin determinations were made in triplicate. 


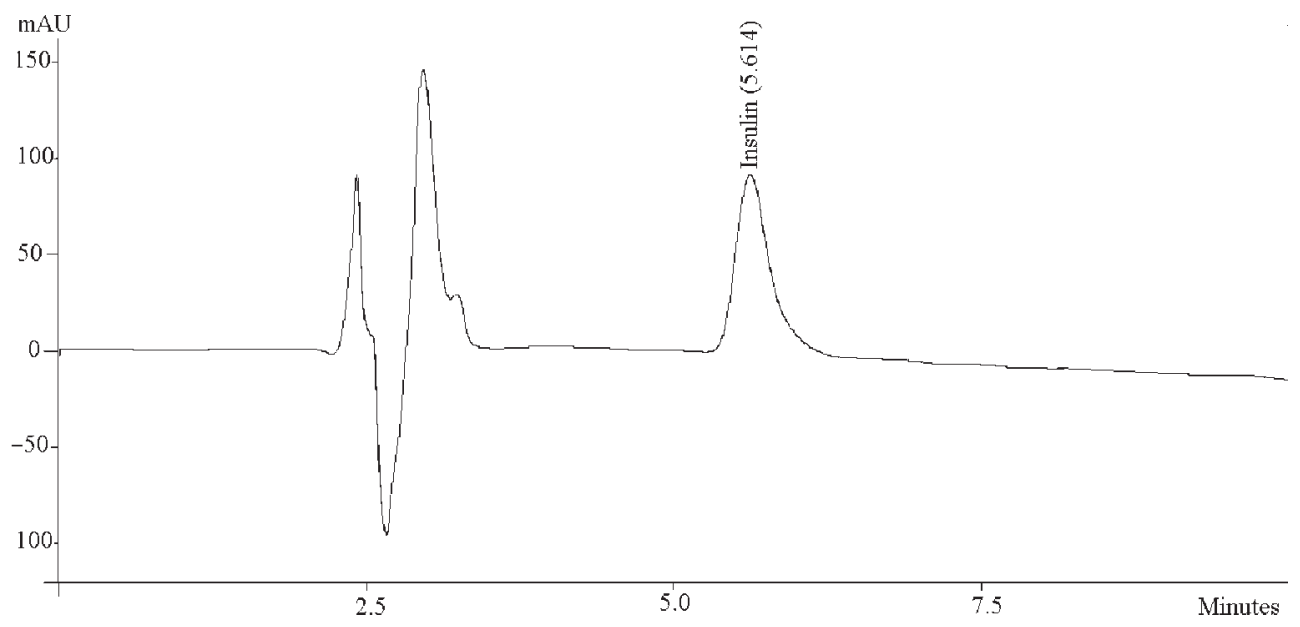

Figure 1. Representative chromatogram of insulin detection.

To establish the insulin release profile from nanoparticles at simulated gastric and intestinal $\mathrm{pH}$, nanoparticles were placed into test tubes containing $20 \mathrm{~mL}$ of USP XXVI HCl buffer $\mathrm{pH} 1.2(120 \mathrm{~min} / 100 \mathrm{rpm})$ or USP XXVI phosphate buffer $\mathrm{pH} 6.8(120 \mathrm{~min} / 100 \mathrm{rpm})$. At appropriate intervals aliquots of $100 \mu \mathrm{L}$ were taken and replaced by fresh medium. Aliquots were centrifuged at $5000 \mathrm{~g}$ for $15 \mathrm{~min}$ to eliminate possible insoluble polyions and the amount of insulin released from the nanoparticles was evaluated by HPLC as described above.

\section{RESULTS AND DISCUSSION}

\section{Optimization of the chromatographic method}

An optimized reversed-phase HPLC method for the assessment of human insulin associated with nanoparticulate carriers has been proposed. Previous experiences were exploited to provide a simple procedure with the best chromatographic peak resolution, reduced run time and low cost of analysis. All these factors contribute to the establishment of an analytical method which permits the analysis of a large series of samples and avoiding possible degradation due long analysis time. A typical chromatogram for the proposed method is depicted in Fig. 1. The relatively symmetrical insulin peak has a retention time of $5.614 \mathrm{~min}$.

Additionally, no peak from possible degradation products, as mentioned in other investigations (Oliva et al., 2000), was observed in the chromatograms, showing the purity of insulin used and its stability in stock solutions. Nevertheless, degradation products of insulin could be promoted by heating and agitation. These procedures were not carried out for standard solutions used in the validation of this method.

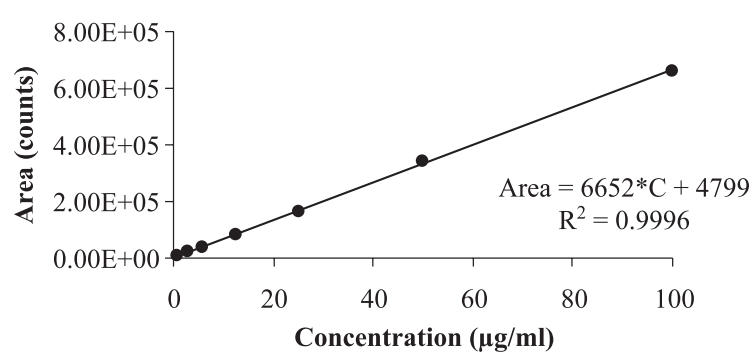

Figure 2. Calibration curve obtained with insulin standard solutions using the proposed HPLC method $(n=21)$.

\section{Method validation}

Linearity. Calibration curves for seven human insulin standard solutions of different concentrations ranging from 1 to $100 \mu \mathrm{g} / \mathrm{mL}$ at concentrations of $1,3,6,12.5$, 25,50 and $100 \mu \mathrm{g} / \mathrm{mL}$ were prepared in USP XXVI acetate buffer $\mathrm{pH}$ 4.7. A primary stock solution was accurately prepared followed by rigorous dilution to give secondary standard solutions. Each sample was analyzed three times. A good linearity was obtained in the range of study (Fig. 2). The calibration curve and regression coefficient were:

$$
\begin{gathered}
\text { area }=6652( \pm 89) C+4799( \pm 3455) \\
\text { correlation coefficient }\left(R^{2}\right)=0.9996(n=21) .
\end{gathered}
$$

The $R^{2}$ obtained was higher than 0.999 , as frequently recommended (Épshtein, 2004), indicating a good linearity in the proposed range.

Precision. Precision of the assay was determined by analyzing the samples at three different concentrations. For the assessment of the intra-day variation samples were analyzed in triplicate $(n=3)$ in three different 
Table 1. Results of precision tests for the determination of insulin in standard solutions

\begin{tabular}{lcccc}
\hline $\begin{array}{l}\text { Standard } \\
\text { solution } \\
(\mu \mathrm{g} / \mathrm{mL})\end{array}$ & Day & $\begin{array}{c}\text { Measured } \\
(\mu \mathrm{g} / \mathrm{mL})\end{array}$ & $\begin{array}{c}\text { SD } \\
(\%)\end{array}$ & $\begin{array}{r}\text { RSD } \\
(\%)\end{array}$ \\
\hline $\begin{array}{l}\text { Intra-day variation }(n=3) \\
12.5\end{array}$ & 0 & 13.09 & 0.29 & 2.21 \\
& 5 & 12.56 & 0.44 & 3.48 \\
& 10 & 12.76 & 0.49 & 3.80 \\
50 & 0 & 51.06 & 0.45 & 0.87 \\
& 5 & 50.71 & 0.82 & 1.62 \\
& 10 & 50.51 & 0.70 & 1.39 \\
100 & 0 & 99.74 & 0.36 & 0.36 \\
& 5 & 100.03 & 0.18 & 0.18 \\
& 10 & 99.96 & 0.44 & 0.45 \\
Inter-day variation $(n=10)$ & & & \\
12.5 & & 12.95 & 0.33 & 2.55 \\
50 & & 50.99 & 0.72 & 1.42 \\
100 & 99.90 & 0.24 & 0.25 \\
\hline
\end{tabular}

days; for the inter-day variation they were analyzed 10 times $(n=10)$ in the same day. As depicted in Table 1 the intra-day relative standard deviation ranged from 2.21 to $3.80,0.87$ to 1.62 and 0.18 to 0.45 at $12.5,50$ and $100 \mu \mathrm{g} / \mathrm{mL}$, respectively. Inter-day RSD was 2.55 , 1.42 and 0.25 , for the same concentrations of standard solutions. These results indicate good precision of the analytical method (Bressolle et al., 1997).

Accuracy. The accuracy characterizes the proximity between the obtained experimental results and the real results, and was assessed by the determination of the percentage recovery of a known amount of insulin. Three different standard solutions of 7,28 and $50 \mu \mathrm{g} /$ $\mathrm{mL}$ were precisely prepared as described above, analyzed, and a mean recovery of $100.02 \% \pm 1.04 \%$ was found. To investigate accuracy using another source of insulin, a commercial formulation of insulin, Humulin Regular $^{\circledR}$ was diluted 1:100 in order to obtain a final concentration of $35 \mu \mathrm{g} / \mathrm{mL}$ (within the studied range). A mean recovery of $100.37 \% \pm 0.65 \%$ was found. These results show the agreement between the obtained experimental values and theorical ones. Thus, it can be emphasized that this method is accurate. Table 2 summaries obtained recoveries from different standard solutions, in comparison to a commercial formulation.

Specificity. Specificity of method was verified by analyzing potential interfering peaks of the formulation components at insulin retention time. Pure aqueous solutions of polyelectrolytes (alginate and chitosan) were prepared at the same concentrations used for nanoparticulate production. In addition, empty nanoparticles, i.e. consisting only of alginate and chitosan, were also prepared and further centrifuged to obtain
Table 2. Results of recovery (\%) and RSD (\%) for insulin from standard solutions $(n=3)$

\begin{tabular}{lcc}
\hline Standard solution $(\mu \mathrm{g} / \mathrm{mL})$ & Recovery $(\%)$ & RSD $(\%)$ \\
\hline 7 & 98.86 & 2.75 \\
28 & 100.88 & 0.77 \\
50 & 100.30 & 0.63 \\
35 (Diluted Humulin $^{\circledR}$ ) & 100.37 & 0.65 \\
\hline
\end{tabular}

Table 3. Robustness of proposed method in terms of recovery (\%) and RSD (\%) for $7 \mu \mathrm{g} / \mathrm{ml}$ insulin standard solutions at different pH $(n=3)$

\begin{tabular}{lcc}
\hline $\mathrm{pH}$ of insulin & & \\
standard solution & Recovery (\%) & RSD (\%) \\
\hline 1.2 & 99.71 & 1.17 \\
4.7 & 98.86 & 2.75 \\
6.8 & 100.14 & 2.07 \\
\hline
\end{tabular}

the supernatant. Three injections of each solutions, i.e. alginate solutions, chitosan solution and supernatant, were performed in same conditions as previously described for insulin detection. The main purpose was to detect any retention peak due to any isolate polymer or combination of them. No interfering peaks were observed. Therefore, this method was found to be specific.

Detection Limit (DL) and Quantitation Limit (QL). The DL can be defined as the lowest concentration of analyzed substance in a certain sample that can be detected under certain conditions by a given method. $\mathrm{QL}$ is the lowest concentration that can be determined at an acceptable precision and accuracy. These definitions were first introduced by $\mathrm{ICH}$ and nowadays are generally accepted. Several alternatives are described to determine DL and QL (Épshtein, 2004). In the present work, these parameters were established from the SD of the response and the slope of the calibration curve. Values of SD were calculated from standard deviation of the free terms taken from regression equations of calibration curves obtained using reference samples in the region of $\mathrm{LD}$. $\mathrm{LD}$ and $\mathrm{QL}$ were found to be 0.24 and $0.72 \mu \mathrm{g} / \mathrm{mL}$, respectively. These values are slightly lower than those found in previous studies (Kunkel et al., 1997; Moslemi et al., 2003; Oliva et al., 2000), which can be pointed as an advantage compared with other methods.

Robustness. The evaluation of robustness was based on the recovery and RSD values obtained using insulin standard solutions of different $\mathrm{pH}$ (Table 3). This approach has the advantage of prediction of the application of the method not only for small variations of $\mathrm{pH}$ during the production of nanoparticulate, but also for insulin release at simulated gastric and intestinal conditions. Insulin solutions $(50 \mu \mathrm{g} / \mathrm{mL})$ 
prepared with $\mathrm{pH} 1.2,4.7$ and 6.8 buffers were tested and values were evaluated in terms of recovery (\%) and RSD. The low values of RSD $(1.17,2.75$ and 2.07$)$ and high values of recovery (99.71, 98.86 and $100.14 \%$ ) indicate that this analytical procedure is robust with respect to sample $\mathrm{pH}$ and allows its use for further insulin determinations from same nanoparticulate systems.

Application of the method. The proposed method was applied to study insulin association with nanoparticulate carriers produced by ionotropic pre-gelation of calcium ions and alginate reinforced with chitosan polycation. The carriers were prepared in an aqueous environment and further centrifuged for their isolation in order to determine indirectly insulin association efficiency that remained in the supernatant after formation of nanoparticulate carriers. Previous experiments were done to establish the ideal formulation and to characterize those nanoparticulates. An insulin AE of 69.30 $\pm 3.80(\%)$ and a LC of $11.17 \pm 0.61(\%)$ were found $(n=3)$, which are highly accurate results as compared with the colorimetric method (Sarmento et al., 2005). No insulin degradation peak was detected. The AE was also evaluated during the shelf life in order to assess the protein stability associated with the carriers. After one month of storage at $4{ }^{\circ} \mathrm{C}$ the $\mathrm{AE}$ decreased to $58.70 \pm 5.79$. It was demonstrated that none of other nanoparticle components interfered with insulin determination, but a centrifugation step was required to protect the HPLC column from contamination and delay pre-column obstruction.

The representative insulin release-time profile from nanoparticles in gastric and intestinal $\mathrm{pH}$ simulated conditions is illustrated in Fig. 3, as a suitable application of this method. Insulin release was characterized by an immediate burst effect, in both media. Up to $50 \%$ of insulin was released from nanoparticles within 5 min of contact with both acidic and intestinal environments and a cumulative release of $75 \%$ occurred after $2 \mathrm{~h}$. These results seem to indicate that a significant amount of insulin initially associated with nanoparticles

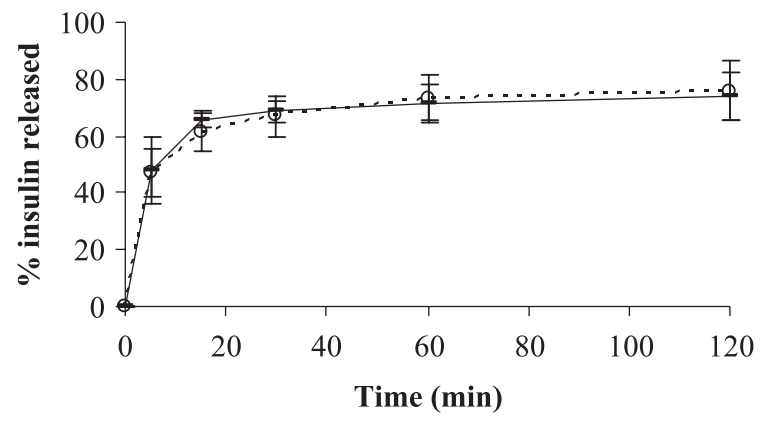

Figure 3. Mean $( \pm \mathrm{SD})$ insulin release from nanoparticles at gastric $\mathrm{pH} 1.2$ (open circles) and intestinal simulated $\mathrm{pH} 6.8$ (solid squares) $(n=3)$. remained on their surfaces by weak linkages to polymers and alginate nucleus did not have the necessary strength to entrap all protein. Also, a considerable fraction of insulin, 30\%, can conserve a stable interaction with nanoparticles after being placed in contact with both aqueous simulated gastric and intestinal release medium for $2 \mathrm{~h}$. After $2 \mathrm{~h}$ of assay, no detectable hydrolysis degradation products of insulin and only a well-defined peak appeared on the chromatogram, indicating that nanoparticulate carrier could retain insulin primary structure during encapsulation. Partial protection against insulin release can be attributed to the alginate-calcium ions network that pre-gel can provide against insulin diffusion (Coppi et al., 2002; Vandenberg and De La Noue, 2001).

\section{CONCLUSION}

This study has described a new, rapid and validated RP-HPLC method for insulin determination according ICH guidelines. All parameters are within the limits proposed by those guidelines for pharmaceutical formulations, indicating that this method is specific, precise, accurate and robust with low detection and quantification limits. Furthermore, suitable application for insulin in vitro analysis can be assumed during formulation development and characterization. The proposed method was used to predict the association efficiency and the release profile of insulin from nanoparticulate carriers composed of contrary charged polysaccharides. Insulin entrapment is essentially by reversible ionic interactions, which permits an absence of interaction of polymers on protein determination in the different steps of formulation development.

\section{Acknowledgments}

This work received support from Fundação para a Ciência e Tecnologia (FCT), Portugal. Bruno Sarmento is the recipient from a scholarship from FCT. The authors wish to thank Lilly Farma for insulin supply.

\section{REFERENCES}

Aboubakar M, Couvreur P, Pinto-Alphandary H, Gouritin B, Lacour B, Farinotti R, Puisieux F and Vauthier C. Insulin-loaded nanocapsules for oral administration. In vitro and in vivo investigation. Drug Development Research 2000; 49: 109.

Aguilar MI. HPLC of peptides and proteins: basic theory and methodology. Methods in Molecular Biology 2004; 251: 3.

Brange J, Andersen L, Laursen ED, Meyn G and Rasmussen E. Toward Understanding Insulin Fibrillation. Journal of Pharmaceutical Sciences 1997; 86: 517.

Bressolle F, Bromet-Petit M and Audran M. Validation of liquid chromatographic and gas chromatographic methods Applications to pharmacokinetics. Journal of Chromatography B: Biomedical Sciences and Applications 1997; 686: 3. 
Coppi G, Iannuccelli V, Leo E, Bernabei MT and Cameroni R. Protein immobilization in crosslinked alginate microparticles. Journal of Microencapsulation 2002; 19: 37.

Épshtein N. Validation of HPLC techniques for pharmaceutical analysis. Pharmaceutical Chemistry Journal 2004; 38: 212.

Hari P, Chandy T and Sharma CP. Chitosan/Calcium-Alginate Beads for Oral Delivery of Insulin. Journal of Applied Polymer Science 1996; 59: 1795.

ICH. International Conference on Harmonization (ICH) of Technical Requirements for the Registration of Pharmaceuticals for Human Use, Validation of Analytical Procedures: Methodology (ICBQ2B), 1996.

Khaksa G, Nalini K, Bhat M and Udupa N. High-performance liquid chromatographic determination of insulin in rat and human plasma. Analitycal Biochemistry 1998; 260: 92.

Kunkel A, Günter S, Dette C and Wätzig H. Quantitation of insulin by capillary electrophoresis and high-performance liquid chromatography method comparison and validation. Journal of Chromatography A 1997; 781: 445.

Marschutz MK and Bernkop-Schnurch A. Oral peptide drug delivery: polymer-inhibitor conjugates protecting insulin from enzymatic degradation in vitro. Biomaterials 2000; 21: 1499.

Michel C, Aprahamian M, Defontaine L, Couvreur P and Damgé C. The effect of site of administration in the gastrointestinal $\operatorname{tr} \mathrm{ACN}$ on the absorption of insulin from nanocapsules in diabetic rats. Journal of Pharmacy and Pharmacology 1991; 43: 1.
Moslemi P, Najafabadi AR and Tajerzadeh H. A rapid and sensitive method for simultaneous determination of insulin and A21-desamido insulin by high-performance liquid chromatography. Journal of Pharmaceutical and Biomedical Analysis 2003; 33: 45.

Oliva A, Farina J and Llabres M. Development of two highperformance liquid chromatographic methods for the analysis and charACNerization of insulin and its degradation products in pharmaceutical preparations. Journal of Chromatography B 2000; 749: 25 .

Onal S and Zihnioglu F. Encapsulation of insulin in chitosan-coated alginate beads: oral therapeutic peptide delivery. Artificial Cells, Blood Substitutes, and Immobilization Biotechnology 2002; 30: 229.

Sarmento B, Ferreira D, Ribeiro A, Veiga F and Neufeld R. Production of chitosan-coated insulin-loaded alginate nanoparticles by ionotropic gelation. XIIth International Workshop on Bioencapsulation, Vitoria, Spain, 2004.

Sarmento B, Ribeiro A, Veiga F, Neufeld R and Ferreira D. Insulinloaded alginate/chitosan nanoparticles produced by ionotropic pregelation. Revista Portuguesa Farmácia 2005; LII: 139.

Takenaga M, Yamaguchi Y, Kitagawa A, Ogawa Y, Mizushima Y and Igarashi R. A novel sustained-release formulation of insulin with dramatic reduction in initial rapid release. Journal of Controlled Release 2002; 79: 81.

Vandenberg GW and De La Noue J. Evaluation of protein release from chitosan-alginate microcapsules produced using external or internal gelation. Journal of Microencapsulation 2001; 18: 433. 